\section{Distance Education, Multimedia and the Internet}

\author{
GRAHAM WAGNER AND ERROL JAQUIERY ${ }^{1}$
}

\section{Abstract:}

Multimedia approaches to distance education have been mooted for further development at a time when there is less government involvement in New Zealand education. The Internet is a likely resource for exploitation by distance education institutions. Not only does the Net appear to be a huge source of information for teachers and students, but it could also serve as a testing bed for multimedia teaching/learning applications. However, the use of the Internet involves connectivity, system familiarity, and social and cultural issues. Because of the need to resolve these issues, this paper reiterates the necessity for a comprehensive national distance education policy.

hen Stevens and Tate (1993) wrote in the New Zealand Annual Review of Education on the changing nature of distance education during the period 1992-93, their main concern was that in a strategic sense the country lacked a comprehensive distance education plan. Of primary interest to these writers, at that time, was the need for a coherent and comprehensive policy to deal with the logistical demands endemic in the growth of a burgeoning distance education industry. The writers were also concerned that provisions be made to bridge the gap between the development of information and communications technologies, on the one hand, and the implementation of appropriate distance education pedagogies, on the other. Preparing teachers to deal with the plethora of new communications technologies and software was then, and still is, a necessary prerequisite to realising the full potential of distance education in New Zealand.

This paper builds on the position outlined by Stevens and Tate by investigating not only the opportunities a multi-media approach to distance education offers both distance educators and isolated students, but important matters that have come to the fore since the advent of the

\section{Graham Wagner and Errol Jaquiery}

Internet (or Net for short). In particular we address the issues of connectivity, the Internet and democratisation of communications, student and teacher needs in dealing with technology, the cost of innovation, and appropriate technology. We reinforce Stevens and Tate's concern that the further development of communications and information technology in New Zealand requires a comprehensive distance education plan.

\section{Definitions}

"Distance education", "open learning" and "open access" are terms that are often used in relation to one another, yet the contextual meanings are often blurred. "Distance education", as we use it in this paper, is the linking of an instructional source using any medium with a learner isolated by time and location. "Open learning" is an arrangement whereby people can learn in their own way by any means that overcomes barriers to their participation such as geographical isolation, personal and work commitments, or institutional course structures.

"Open access", in contrast to the previous two definitions, is an educational and political philosophy espousing equality of opportunity through open access; in other words, entry to training providers' courses (upon payment of a small registration fee) by students irrespective of age, gender, ethnicity, previous educational qualifications, or formal entrance requirements (Jones et al., 1992, pp. 37-38). A confusion between open learning and open access is evident in some recent publications (Parent and School, 1993; Buckrell, P. et al., 1992), but the majority of people working in distance education are usually aware of the difference.

\section{Media Technologies}

Traditional formal distance education institutions in New Zealand such as the Correspondence School, The Open Polytechnic, Otago University's Extension Unit, and Massey University's Department of Extramural Studies (now incorporating the Advanced Studies for Teachers Unit) have all trialled one or more of the newer communications technologies. Multi-media applications (the simultaneous, combined use of several media at once) in New Zealand distance education, for the most part are relatively modest, but there is an expanding use of different media. Depending upon the institution, courses are provided that may use a combination of correspondence texts, broadcasts, audio tapes, home kits, some face-to-face contact, modems, free dial-in tutoring, audiographics, and audioconferencing. 
A survey of the most popular media in distance education institutions in the Northern Hemisphere (Sherry, 1996) demonstrates a penchant for multimedia applications, including the Internet:

- computer-based communication including electronic mail (E-mail); bulletin board systems BBSs, and the Internet;

- telephone-based audioconferencing;

- audiographic teleconferencing using slowscan or compressed video and facsimile;

- videoconferencing with 1 - or 2-way video and 2-way radio via broadcast, cable, telephone, fibre optics, satellite, microwave, closedcircuit or low power television;

- Mosaic (and other graphical interfaces) to access the World Wide Web on the Internet.

While much is being made overseas of third generation information technologies and the need for distance education to be interactive (Buckrell, 1992), the main players in New Zealand distance education are building on their print and mail resources by extending delivery and communication modes to include some of the new media.

\section{Contemporary Approaches to Multimedia Distance Education \\ Applications}

In line with overseas practices, especially those initiated by the Open University in the United Kingdom (Jones et al., 1992, p. 38), there have been experiments in New Zealand with media such as telephone tutoring, television programming, video cassettes, audio-graphics conferencing, and personal computers which have led to effective applications of these different forms of delivery. For example, the Open Polytechnic has used an 0800 service to allow students to telephone their tutors, and has experimented with audiographics and teleconferencing. Massey University extramural courses have been supplemented with computer disks, E-mail and television broadcasts. The Correspondence School offers an 0800 system for students to contact their tutors, has added new CD ROM disks to its multimedia offering, and is currently experimenting with Interactive Satellite Television (ISTV). A newcomer to distance education (Hutt Valley Polytechnic), is using an 0800 telephone tutoring system for on-job training in some of its automotive trades courses.

The Ministry of Education, in line with current Government policy, lets the market determine what is needed in education and training (McMillan, 1995). Ministry policy papers to Government are confidential because of the budgeting information they contain. However, the Ministry acknowledges and supports policies already laid down in key documents, such as the curriculum framework (Ministry of Education, 1993) and technology curriculum (Ministry of Education, 1994), by financing key research projects. For example, in recent times, to stimulate activity in using information technology for distance education, the Ministry has funded a number of research projects at the New Zealand Correspondence School (NZCS). ${ }^{2}$ These are: a study of desktop video conferencing; a second study on the development of CD ROMs in mathematics and languages; and currently, a study in 90 schools around New Zealand on the impact of satellite technology in enhancing student learning and teacher professional development. ${ }^{3}$

Apart from an up-to-date account of a range of current studies on the use of information technology in education contained in the New Zealand Computers in Education Society's Conference Proceedings (1996), the last-mentioned study is perhaps the most significant for distance education in New Zealand. Not only is this study about a lowcost digital television by satellite broadcasting application, ${ }^{4}$ but it is designed to make the video/audio broadcast two-way, or interactive:

Students (and teachers) will be able to phone or fax The Correspondence School studio during or between broadcasts. It is also important that students complete the work set between the broadcasts. The learning materials have been developed to encourage the students to interact with the subject. The broadcasts will pause, from time-to-time, to allow the local teacher to engage the students in a related activity. (Donovan, 1996, p. 98)

Morris (1996), like others before him (US Congress, 1988; Griffin, 1993; Simon, 1994; Schlosser \& Anderson, 1994), has recently argued for distance education methodologies which allow for pupil-teacher interaction in the New Zealand context. He lists the following contemporary multimedia communication technologies as providing the level of immediacy necessary to meet the needs of distance education students:

- Interactive Television (ITV)

- CUSeeMe

- E-mail - modified with Lotus ScreenCam2 
- SVD (Simultaneous Voice Data) modems

- I-phone

- IRC (Internet Relay Chat, similar to BBS chat)

- WWW (World Wide Web)

- MOOs - Multi-user Object Oriented systems (Morris, 1996, pp.183188).

The interesting point to note about Morris's list is that these technologies are used over the Internet. The Internet is now being seen as the new frontier for distance educators. Early indications are that it has great potential for all comers and will be able to provide support for open learning and/or distance learning, individualized learning and interactive learning. We need no longer consider print media as the primary media application in the future:

...we can look beyond the printed word, and find our way into the digital world that forms the basis of an Information society. The reality of the Internet has come about so fast and so rapidly into some information societies that the ability to be able to communicate through this medium is being considered as much a part of daily living in much the same way that the mobile phone is being used for business communication and ordinary conversation. (Voon, 1996, p. 55)

Visionaries like Professor Voon think we should look beyond the present use of the "infobahn" for basic communication and information products, to new forms of learning and new learning environments. But before distance students and their teachers go "surfing on the Net", there are economic and educational realities that need to be considered. Just grappling with what the Internet is, and how it operates, is a major task for all new initiates to the "electronic super highway".

\section{The Internet}

With the large increase in the use of low cost computers, and readily available access to telecommunications networks, a wide range of new technologies become available for use by distance education providers. The one with the most promise to educators, because of its low cost and relatively easy access to a range of information resources, is the 26 year old global computer network known as the "Internet". Not only is it possible to send E-mail messages to different "addresses" all round the globe, but its multimedia application, the World Wide Web (WWW or simply the Web), gives access to different "sites" and a range of complex materials including charts and tables, drawings and diagrams, photographs, video images, and music:

With Web access, you have the world at your fingertips. You can check out the latest news or weather from around the world, preview movies, find out what's happening in Parliament, read up on the latest gene discoveries, join a skydiving club or go shopping. (Consumer, December 1995, p. 25)

Nielson Media Research ${ }^{5}$ in the United States has reported that 37 million people (age 16 and older) in the US and Canada have access to the Internet. In their November 1995 survey Nielson also discovered that:

- 24 million North Americans used the Internet in the past three months (this represented $11 \%$ of the population of 16 and older)

- users spend an average of $5 \mathrm{hr} .28 \mathrm{~min}$. on the Internet per week

- $34 \%$ are women

- $66 \%$ reached the Internet from work

- $25 \%$ of World Wide Web users have incomes of more than $\$ 80,000$. (Dibbell, 1995, p. 78)

While there are no definitive figures on the number of Internet users world-wide, nor in New Zealand, ${ }^{6}$ the potential of the Net for home users, and education and training providers, is simply enormous. Even so, there has been a cautionary note expressed publicly about accessing the Internet: And yet, precisely because of its vast potential, the Internet is
complex to understand and difficult to use. It can also involve big costs. (Consumer, December 1995, p. 25)

Use of the Internet assumes a fast computer, telephone line, modern modem, sound systems and video cards, printer communications software and access to a Service Provider (e.g., CompuServe, and PlaNet FreeNZ to name just two of the more popular ones). The costs involved in getting on-line, and then using the E-mail and WWW facilities on a regular basis, can turn out to be quite substantial. The Consumers' Institute estimated that a moderate user of the Web, working through one of the cheapest providers (PlaNetFreeNZ), would run up a monthly 
bill of around $\$ 23.50$ (Consumer, December 1995, p. 29). This may not seem a lot of money to computer enthusiasts, but when this cost is added to distance education students' study time and other study expenses then the Internet may appear to be more of a "could have", rather than a "must have", option for home study.

Yet the question still arises: "Will a distance education student in the future be at a considerable disadvantage in not having access to the Internet?" Pita Keegan, speaking mainly about Maori educational opportunities, sees the Internet and the WWW taking over from textbased networks in New Zealand. In his view:

A number of New Zealand secondary schools have their own Web pages. Some schools have become full Internet sites. NZ Online promises Web presence in 1996. The Ministry of Education is funding a "trial project" where a number of schools have been given access to assessment resource banks in mathematics and sciences through the Web. The expansion of resources and network capabilities for New Zealand teachers and students will undoubtedly continue. (Keegan, 1996, p. 50)

Keegan, nevertheless, recognises that this expansion will take some time to achieve. In addition, he comments that there are still problems associated with cost, bandwidth and IP (the unique address given to every computer on the Internet). Yet the possibilities for Maori medium education ${ }^{7}$ are, in his words, "mind boggling". Not only does the Internet provide the means to enhance and empower the Maori community, but it gives Maori users access to a huge array of information resources (Keegan, 1996, p. 51). The same could be said for anyone engaged in using the Internet.

\section{Complexity of the Net}

Assuming that connectivity is not a factor, as is the case in New Zealand, three major issues arise when using the Internet facilities for other than the relatively simple text-based E-mail option. These are: learning to use the system (commands and data management) and its language; dealing with the torrent of information; and censorship and copyright. Taking up the first issue, it will be necessary for distance education users to master their computers and the necessary communications software to access both the "shell" and "PPP/SLIP" connections of the Internet Service Provider; learn about Usenet newsgroups (there are more than 12,000 around the world), ftp, gopher and telnet not to mention MUDs,
MOOS and IRC); acquire and use graphical interfaces to the WWW facility if holding a PPP or SLIP account; and learn something about Net culture and Netiquette (Merritt \& Reynolds, 1995). And if this is not enough, there are the safeguards one must take to ensure that computer viruses are not introduced from Net activities into one's own personal computer or LAN. In sum, already-stretched distance education students, usually with little time to spare, may have enough on their plate studying at a distance through traditional means, let alone having to grapple with a complex new system of learning.

\section{Information Overload}

The second issue that arises is that any Internet user will be confronted with a literally overwhelming torrent of information. To quote the Consumer's Institute again: "Anyone can get at it, and anyone can add to it. But that is a weakness as well as a strength" (Consumer, 1995, p. 28).

The Internet may "democratise information", but this freely available information comes at a price. Comments and articles that surface in the Net's newsgroups do not have to go through the rigorous review process of a reputable journal. It is likely, therefore, that contained in the huge volume of information on the Net there will be significant misinformation and many comments of dubious value to most users. It takes considerable time to judge the validity of the information at one's disposal on the Net.

Yet, in spite of this caution, the Internet can prove to be a valuable source of information for those with the time to "surf". To bring order to the scene there are excellent user guides (e.g., Merritt \& Reynolds, 1995) and some ingenious search programmes for finding documents and sites of interest. ${ }^{8}$ And, in accordance with the democratic nature of the Internet, much of the Net software available to educational users is available as "shareware".

\section{Censorship and Copyright}

The third issue facing the user is the threat of censorship, or copyright, blocking or restricting access to information. As mentioned above, the Internet democratises information by making so much of it available to so many people throughout the world. When a problem arises where a Service Provider is required by a nation-state to shut off access to a group of its clients, then all its clients are deprived access to the section in dispute, as an Internet Service Provider, CompuServe, proved recently. ${ }^{9}$ However, while CompuServe deprived its clients of access to 
the disputed newsgroups, other users outside CompuServe are not, as yet, affected. In this case: "The Net interprets censorship as damage and routes around it" (Barlow, 1996, p. 57)

While parents may have every right to censor their children's access to certain databases on the Net, ${ }^{10}$ censorship is a growing concern for the whole Internet community. Germany, the Peoples' Republic of China, and the US are all seeking ways to limit their citizens' access to the Net "using prurience as their longest lever":

The real issue is control. The Internet is too widespread to be easily dominated by any single government. By creating a seamless global-economic zone, borderless and unregulatable, the Internet calls into question the very idea of a nation-state.

No wonder nation-states are rushing to get their levers of control into cyberspace while less than $1 \%$ of the world's population is online. (Barlow, 1996, p. 57)

In addition to censorship, there is a further concern, especially in the United States, about the relationship between the Net and copyright law which, as one writer put it, "simply has not caught up with technology" (The Times, 1996, p. 11). Charlesworth (1996, vii) argues that there are aspects of the Web that have important copyright implications. These are: the layout of the Web page; the role of a Web server in allowing access to infringing materials though links to other sites; and, the matter of caching (or storage of information at one central site). And there is more. There has even been controversy over domain names.

It is academics who have contributed most to the Internet, and they have the most to lose from government regulation on behalf of publishers and state institutions. They have a vested interest in the openness of the Internet, something that they now need to debate on a global basis:

Otherwise, academics may find that every time they publish a paper, write a textbook, distribute notes to students or visit the library, they have to operate by rules designed not for a community of scholars, but for the multimedia entertainment industry. (The Times, 1996, p. 11)

Putting aside political and economic factors for the moment, there are still educational factors that need to be considered before one uses the Internet for distance education. Too often those involved in the delivery side of education (instructional designers and curriculum developers) have "become enamoured of the latest technologies without dealing with underlying issues" such as learners' and teachers' needs and the influence of media upon the teaching/learning process (Sherry, 1996, p. 1).

\section{Students, Teachers and the Internet}

We know from previous research (Ostman et al., 1988; Willis, 1993) that students study via the distance mode for a wide variety of reasons constraints of time, distance, and finance are the most common - but they also have a preference for a particular mode of learning, such as cooperative, competitive or individualized (Johnson \& Johnson, 1974). Learning styles such as the need for greater autonomy in learning, active listening skills and the ability to work independently have been found to be crucial success factors in a number of studies (Ostman \& Wagner, 1987; Charp, 1994; Godfrey, 1994, cited in Sherry, 1996):

Many current distance education projects incorporate cooperative learning, collaborative projects and interactivity within groups of students as well as between sites. (Sherry, 1996, p. 9)

Distance education teachers are more than traditional classroom disseminators of knowledge and understanding (Perraton,1988). By choosing the most appropriate interactive media to simulate face-to-face teaching they are now facilitators of learning in search of the virtual classroom (Tiffen \& Rajasingham, 1995). Furthermore, judiciously using the Internet as a learning resource, they and their students can form "virtual" learning communities

... in which students and researchers throughout the world who are part of the same class or study group can contact one another at any time of the day or night to share observations, information, and expertise .... ( Sherry, 1996, p. 4)

Nevertheless, it is when the distance teacher recognises the existence of the different learning styles of students, then matches the needs of students with the most appropriate mode of instruction and course content, that student success (i.e., course completion) is most likely. Interactivity is a crucial factor in finding out what students need. Interactive multimedia applications (including the Web) assist in breaking down the distance gap, but there is still a difference between what a face-to-face teacher and distance education in a studio can achieve:

Site facilitators have the advantage of eye-to-eye contact and personal contact with students in their classrooms, whereas studio teachers must rely on televised images, telephone 
conversations, or electronic messaging for feedback of student preferences. (Sherry, 1996, p. 9)

It is clear from what has been said in this country (Stevens and Tate, 1993; Stevens, 1995), and overseas (The Office of Technology Assessment, 1988), that the quality of distance education is predicated on the quality of teachers' training in, and familiarity with, multimedia systems and applications. Just as there is no one best way to teach using technology, there is no one best use of technology. In the OTA report stress was made of the need for flexibility so that teachers could develop their own teaching methods in utilizing technology (US Congress, 1988, p. 17). The challenge to distance education providers today is to offer a sufficient level of teacher training to deal with multimedia technology applications and provide students with the levels of interactivity they require. Carrying out studies on the use of new media for educational use, as mentioned above and outlined in the New Zealand Computers in Education Society 1996 Conference Proceedings (see References), is a necessary component in providing the right kind of learning environment for distance education students.

Research studies into multimedia applications in education do not touch all teachers who need to know about, and experience, appropriate new technology applications, no matter how well publicised they are. A certain amount of training can be done on-the-job, but this never proves to be entirely satisfactory. Formal training is costly and not always available to those who need it, at the time they need it. An interim measure for teachers with access to the Net, is to take entire Internet courses in distance education and theory via E-mail and the WWW:

These courses span the boundary between formal and professional learning, in that not only is a formal course experience presented, but also teachers have the opportunity to extend the specified course with access to other resources and with permutations on contacts and communication with the remote experts which can lead into on-going professional learning behaviours and patterns. (Collis, 1996, p. 20)

\section{Cost of Multimedia Applications}

This topic has been left until last, not because it is a low priority in the production of multimedia programmes for distance education, but because cost alone should not be allowed to stifle the development of appropriate delivery applications. Costs related to information technology, such as computers and computer software, have decreased significantly over the years as the quality of hardware and software has risen. Even telephone tolls, fibre optic cable, and switching devices costs have come down through new developments in technology and competitive pricing. This has led one commentator to predict" the death of distance", and in the near future, the introduction of "near free communications" (Cairncross, 1995).

Cairncross (1995, pp. 29-30) believes that the end of monopoly PT\&Ts, intense competition between telephone and cable companies with the ever-increasing use of wireless telephony (cf. cellular telephones, and the newly developed "personal handyphone system", which is more economical in its use of available bandwidth), will turn attention away from the communications networks to what goes over the networks (i.e., software). It is the software that will "cost" the user in the future. Distance education institutions have a virtual monopoly control over this aspect through what they say their students should study.

In spite of these insightful predictions, purchasing and maintaining appropriate multimedia equipment, not to mention the still considerable access network charges, have to be taken in to consideration in the shortterm. The decentralized, flexible learning relationship model used by many distance education institutions means that administrators have to grapple with balancing budgets with low-cost multimedia options. It has been suggested that the high cost of producing, for example, highquality instructional television programmes in the US has risen from the 1962 price of about $\$ 165$ per 15-minute programme, to today's price of about $\$ 3000$ per minute (Cambre, 1991, p. 269). One way around these high production costs is for distance education institutions to cooperate over production, as they often have similar core curriculum development needs.

Because of the resource-intensive nature of distance education productions and the need for fiscal responsibility and accountability, downsizing project development or extending the development time frame are realistic considerations (Schlosser \& Anderson, 1994). Another factor to take into account is that the cost/benefit of technology can vary according to the needs of the education provider, its teachers and its students. Distance education teachers, for example, will not be able to behave as if they are in a virtual classroom if their classrooms are not wired for at least telephones, modems, software and computers (Pournelle, 1994).

It has been demonstrated above that teachers are a crucial 
component in providing quality distance education programmes. They are an asset that their employing body can invest in with the knowledge that there will be substantial professional growth as well as a financial return on their investment:

The more transparent the media are to them, the better service they will deliver. This has a financial payoff too: the better a teacher works with the media, the less necessary the expensive elements of distance delivery coursework (like graphics and sophisticated editing) become to the creation of a quality product. (Holloway \& Ohler, 1991, p. 264)

\section{Conclusion}

This paper has investigated issues that arise when considering the use of the Internet as a distance education resource. With the range of new multimedia applications available, both outside and inside the Internet, teachers are now faced with a new communications system that has special appeal for distance teaching and learning. While the possibilities of the new telecommunications technologies and the Internet are staggering, people working in distance education find their daily time still taken up with traditional methods of delivery based upon written texts and "slow" mail. Yet, as has been demonstrated above:

Telecommunications technologies offer a previously unavailable interactive promise; one that, it could be argued, fits in well with constructivist education and classroom strategies, e.g., in technology education as opposed to educational technology. (Morris, 1996, p. 179)

While the theoretical approach to technology education and training may be in dispute (McMillan, 1995), the time is right to assess where New Zealand is going in distance education. Further, because of the distractions and expense in developing new technologies, it would appear necessary in resourcing schools with technology to concentrate more on the needs of students and teachers and the use of appropriate information and communication technologies. Appropriate in the sense that: distance educators are well trained in providing multimedia delivery systems; there are sufficient resources available to develop multimedia presentations; and students have the means and the will to use these high-profile but relatively more expensive teaching/learning methodologies. If a large enough proportion of students are not familiar with, or do not feel happy about, the technology they are provided with, then valuable resources that have been diverted from other sections of the education budget will be wasted.

There is more to technical progress in distance education than simply providing access to a range of information and communication technologies. There are personal, social and cultural factors that need to be addressed along with the introduction of new ways to communicate. Technological change after all "... is fundamentally a social process, not an event" (OECD, 1988, p. 11). Arthur C. Clarke, the communications satellite pioneer, takes this issue even further when he says:

I don't believe a civilisation can advance technically without corresponding moral progress. If the two get out of step, it will self-destruct, as ours is in danger of doing. (Sherwell, 1996, p. 9)

It is the authors' contention that real progress towards effectively harnessing advanced technologies needs sharply-focused leadership at governmental and bureaucratic levels. While market forces have achieved considerable advances in the education sector, in a small country like New Zealand, ineffective technology coverage and economic inefficiency are likely outcomes. At the very least, centralised policy formulation and substantial seeding funds will be essential if the country's commitment to equity of educational opportunity is to be realised. Rather than wait for this to happen, the time is now opportune for educators to focus specifically on distance education teachers' and students' needs and capabilities. The advent of the Internet has made this a necessity, not simply a possibility.

\section{References}

Barlow, P. (1996, January 15). Thinking locally, acting globally. Viewpoint. Time.

Buckrell, P. et al. (1992). The use of telecommunications technologies for the enhancement of educational services. Department of the Prime Minister and Cabinet, Consultel Associates Limited.

Cairncross, F. (1995, September 30). The death of distance. Telecommunications Survey. The Economist, 3-30.

Cambre, M. A. (1991). The state of the art of instructional television. In G. J. Anglin, (Ed.), Instructional technology, past, present and future. Englewood, CO: Libraries Unlimited.

Charlesworth, A. (1996, January 12). Theft by many other names. Multimedia Features. The Times Higher, vi-vii.

Charp, S. (1994, April). Viewpoint. The on-line chronicle of distance 
education and communication, 7(2). Available Usenet Newsgroup alt.education.distance, May 3.

Collis, B. (1996). Telecommunications for teacher support and professional development. In the proceedings of the New Zealand Computers in Education Society 6th Biennial Conference 1996, 14-17 January, pp. 8-24.

Consumers' Institute. (1995, December). The world at your fingertips. Consumer, 25-31.

Dibbell, J. (1995, November 20). Nielson rates the Net. Time, 78.

Donovan, C. (1996). Satellite broadcasts, digital television and low-cost interactive education programmes. In the proceedings of the New Zealand Computers in Education Society 6th Biennial Conference 1996, 14-17 January, pp. 97-101.

Garrison, D. R. (1990). An analysis and evaluation of audio teleconferencing to facilitate education at a distance. The American Journal of Distance Education, 1(1), 7-13.

Griffin, J. (1993, September). Discovery. NZ Science Monthly, 14-15.

Holloway, R. E. \& Ohler, J. (1991). Distance education in the next decade. In G. J. Anglin, (Ed.), Instructional technology, past, present, and future. Englewood, CO: Libraries Unlimited.

Johnson, D. W., \& Johnson, R. T. (1974). Instructional goal structures: Cooperative, competitive, or individualistic. Review of Educational Research, 44, 213-240.

Jones, A., Kirkup, G. \& Kirkwood, A. (1992). Personal computers for distance education. London: Paul Chapman Publishing Ltd.

Keegan, P. (1996). Initiatives in Maori networking. In the proceedings of the New Zealand Computers in Education Society 6th Biennial Conference 1996, 14-17 January, pp. 35-51.

McMillan, B. (1995). Social and educational reform in New Zealand: The promise and threat of information technology. Educational Technology Research and Development, 43(4), 80-92.

McNabb, J. (1994, October). Telecourse effectiveness: Findings in the current literature. Tech Trends, 39-40.

Merritt, D. \& Reynolds, P. (1995). Internet: A New Zealand users guide. Auckland: Penguin Books.

Ministry of Education. (1993). Technology in the New Zealand Curriculum Framework. Wellington: Learning Media.

Ministry of Education. (1994). Education for the 21st Century. Wellington: Learning Media.

Morris, T. (1996). Distance education technology and the impossible dream? In the proceedings of the New Zealand Computers in Education Society 6th Biennial Conference 1996, 14-17 January, pp. 178-190.

New Zealand Computers in Education Society. (1966). Inter Net Works. The proceedings of the 6th Biennial Conference, 14-17 January.

OECD. (1988). New technologies in the 1990s: A socio-economic strategy. Paris: OECD.

Ostman, R. E., and Wagner, G. A. (1987). New Zealand management students' perceptions of communication technologies in correspondence education. Distance Education, 8(1), 47-63.

Ostman, R. E., Wagner, G. A. \& Barrowclough, H. M. (1988). Adult distance education, educational technology and drop out. Studies in Education No. 48. Wellington: NZCER.

Perraton, H. (1988). A theory for distance education. In D. Stewart, D. Keegan, \& B. Holmberg (Eds.), Distance education: International perspectives. New York: Routledge.

Pournelle, J. (1994, July). An educational trip. Byte, 197-210.

"Sandpit". (1995, October). Wordrap. Windows User, 23-24.

Savery, J. R. \& Duffey, T. M. (1995). Problem-based learning: An instructional model and its constructivist framework. Educational Technology, 35(5), 31-38.

Schlosser, C. A. \& Anderson, M. L. (1994). Distance education: Review of the literature. Washington, DC: Association for Educational Communications Technology.

Sherry, L. (1996). Issues in distance education. International Journal of Distance Education (in press), 1-19.

Sherwell, P. (1996, January 25). Space prophet offers world first free energy. The Dominion, p. 9.

Simon, H. A. (1994). Interview. OMNI Magazine, 16(9), 71-89.

Stevens, K. (1995). The development of virtual classrooms in rural New Zealand communities - Some teaching, learning and management considerations. In the proceedings of the New Zealand Association for Research in Education Conference, Massey University, 7-10 December.

Stevens, K. \& Tate, O. (1994). The changing nature of distance education in New Zealand 1992-93: Some strategic considerations. New Zealand Annual Review of Education, 3, 319-334.

Tiffen, J. \& Rajasingham, L. (1995). In search of the virtual class - Education in an information society. London: Routledge.

Net closes on rights. Opinion (1996, January 12). The Times Higher 
Educational Supplement, p. 11

Pulling the plug on porn. (1995, January 8). Time, Technology Section, p. 48.

US Congress, Office of Technology Assessment. (1988). Power on! New tools for teaching and learning. OTA-SET-379. Washington, DC: US Government Printing Office.

Voon, F. C. T. (1996). Internet works: The reality, repercussion and realization for education. Keynote address. In the proceedings of the New Zealand Computers in Education Society 6th Biennial Conference 1996, 14-17 January, pp. 53-64.

Willis, B. (1993). Strategies for teaching at a distance. ERIC Document Reproduction Service No. ED 351008.

\section{Notes}

1. The authors would like to thank those members of their respective organisations who commented on this paper.

2. Don Ferguson, Ministry of Education, in a telephone conversation on 27 January 1996, with the first author.

3. The Ministry of Education is also funding a study at Piopio primary school on the home-use of computers.

4. The instructional programmes will be transmitted by an Intelsat satellite and Sky Orange (free to all New Zealand seconday schools.)

5. Using a random phone-calling interview technique the researchers contacted 4200 North American householders, a large enough sample to be taken seriously.

6. Robert Manion, writing in The Dominion, February 6, 1996, estimated that New Zealand had between 80,000 and 100,000 Internet users.

7. Keegan uses the term Maori medium education to cover both bilingual units and kura kaupapa Maori (Maori immersion schools operating under Maori principles and values).

8. These include Yahoo, Webcrawler, Infoseek, CUSI and Lycos.

9. When asked by the German prosecutors to shut off access to its German clients from 200 discussion groups under question, CompuServe responded by simply shutting down access to all users

$$
\text { p. 48). }
$$

10. There are programmes to do this such as: Net Nanny (WWW and Email) and Surfwatch (WWW and E-mail).

\section{The authors}

Graham Wagner is a Chief Research Officer at the New Zealand Council for Educational Research. His major areas of research are competency analysis strategies, information technology, telecommunications policy, distance education and adult learners. He is currently researching the effects of the introduction of a telephone line for teaching/learning purposes in a sample of New Zealand primary and secondary schools.

Errol Jaquiery is Chief Executive Officer of The Correspondence School. His particular interests lie in management solutions for developments in distance education. He is currently leading the School through a range of enhanced services, technological delivery applications, materials production developments and student achievement initiatives in preparation for a new vision of distance education for the 21st Century.

of these particular groups on its network (Time, 1996, January 8, 